\title{
Unboxing Childhood: Risk and Responsibility in the Age of YouTube
}

\author{
Julie C. Garlen and Sarah Hembruff
}

\begin{abstract}
Julie C. Garlen is an associate professor of childhood and youth studies at Carleton University in Ottawa, Ontario. Previously, she worked in the U.S. South as a primary teacher and early childhood teacher educator. Her research focuses on the ways that cultural practices and discourses shape childhood, early learning, and teacher education. Email: JulieGarlen@cunet.carleton.ca
\end{abstract}

Sarah Hembruff is an undergraduate student at Carleton University, where she is pursuing a major in childhood and youth studies with a minor in sociology. Her current research examines racialized families' experiences of school disruption and online learning during the COVID-19 pandemic. She also works as an educational assistant for the Ottawa-Carleton District School Board.

In this article, we look to viewer responses to James Bridle's TED Talk on children's YouTube to learn about the discursive landscape of childhood in the digital age. We first situate concerns about children's use of YouTube within a history of moral panic and then conduct a thematic analysis of online comments to discover what viewers identify as the central concerns. We "unbox" three emergent themes of responsibility-corporate, parental, and societal-to understand how these themes might help us think about contemporary discourses of childhood "at risk," critical media literacy, and children's agency as social actors on the Internet.

Key words: childhood; media; YouTube; discourse; moral panic
In recent years, toy unboxing has emerged as one of the most popular genres on YouTube, garnering billions of views. The video genre got its start in the early 2000s when creators began uploading videos in which high-tech products like smartphones are slowly removed from their boxes and carefully examined while the creator shares their first impressions. By 2013, the trend expanded to include toy unboxing videos that were specifically geared toward children, beginning with the wildly popular "Surprise Egg" videos in which an adult user named Melissa Lima, known to fans as DisneyCollector, unwrapped chocolate Disney-themed Kinder eggs to reveal the toys hidden inside (Amlen, 2014). Assisted by parents, children soon began appearing in unboxing videos, and by 2018, two popular sites, Ryan ToysReview and FunToys Collector Disney Toys (formerly DisneyCollector), had amassed 38.6 billion views combined. Although there is no public data that documents how often children are watching these particular videos, a 2020 Pew Research Center study in the United States found that $80 \%$ of all parents with children age 11 or younger have allowed their child to watch videos on YouTube, while 53\% say their child watches YouTube content on a daily basis (Auxier et al., 2020). These statistics combined with studies regarding young children's viewing habits in North America (see Clark, 2019; Common Sense Media, 2017) strongly suggest that unboxing videos have become a prevalent, if not ubiquitous, part of many children's digital media diets. As Jaakkola (2020) notes, "content that encounters such massive popularity should be taken seriously and included in discussions of children's media content in order to better understand what constitutes it" (p. 238).

Over the last few years, the sustained popularity of YouTube among young children, particularly unboxing videos-referred to by Kollmeyer (2015) and others as "toddler crack" - has sparked interest and concern among journalists and experts from a range of disciplines (Bridle, 2017; Craig \& Cunningham, 2017; LaFrance, 2017; Marsh, 2015; Nicoll \& Nansen, 2018; Ramos-Serrano \& Herrero-Diz, 2016; Sloane, 2015; Timsit, 2018). One especially outspoken critic is writer and artist James Bridle, who published a 2017 post on Medium titled "Something is Wrong on the Internet," which was later translated into the popular TED Talk "The Nightmare Videos of Children's YouTube." TED (Technology, Entertainment, and Design) is a nonprofit organization dedicated to sharing ideas in the form of short, powerful talks that are typically delivered at a live event and shared online. At the time of our 
analysis, Bridle's YouTube video had recorded 4,110,631 views, while the video on the TED website had recorded $5,958,708$ views. In the concluding lines of his talk, Bridle says, "We need to stop thinking about technology as a solution to all of our problems but think of it as a guide to what those problems actually are, so we can start thinking about them properly and start to address them" (Bridle, 2018b).

In this article, we take seriously Bridle's suggestion and wonder what the unboxing craze and other YouTube media content for young children that has been labelled "addictive" (Timsit, 2018), "bizarre" (Kelly, 2014), and even abusive (Bridle, 2017) might tell us about the "problems" of contemporary early childhood in a time of constantly changing social media and technology trends. Specifically, we look to viewer responses to Bridle's TED Talk to examine the discursive landscape of childhood in the digital age. We begin by situating contemporary concerns about children's use of YouTube within a long history of moral panics, which have shaped the risk-oriented discourses and practices that construct and regulate childhood in the United States context. To further explore the moral panic associated with profit-oriented and predatory media content for children, we analyze adult viewer reactions to James Bridle's TED Talk to discover what these viewers identify as their central concerns relating to young children's YouTube use. We "unbox" the three dominant themes of responsibility that emerge from the viewer comments - corporate, parental, and societal—to understand how these themes might help us think about contemporary discourses of childhood "at risk," critical media literacy, and young children's agency as social actors on the Internet.

\section{Media and moral panic}

Contemporary anxieties about young children's YouTube viewing habits reflect a long history of moral panic over children's exposure to mass media. The term moral panic was first defined as a sociological concept by Cohen (1972), who described it as occurring when "a condition, episode, person or group of persons emerges to become defined as a threat to societal values and interests" (p. 1). As Hall (1978) emphasized, the perceived risk is often exaggerated in public discourse, resulting in a reaction that is disproportionate to reality. Children, so often perceived in modern Western contexts as important primarily for their future contributions to society, have been often at the centre of moral panics concerning dance crazes, youth culture, drug and alcohol use by young people, youth crimes, and the technology and media use of young people (Krinsky, 2008; Jenks, 1996). As Rose (1990) has observed, "the modern child has become the focus of innumerable projects that purport to safeguard it from physical, sexual, and moral danger, to ensure its 'normal' development" (p. 121). A fear of the "disappearance" of childhood-which social critic Neil Postman (1982) described as the erosion of the distinctions between childhood and adulthood-has fuelled moral panics in the Global North since the rise of industrialization in the late $19^{\text {th }}$ century, when the working, "useful child" was replaced by the "economically useless but emotionally priceless child" (Zelizer, 1985, p. 209). The mythology of the priceless child inspired the progressive "child-saving" movement that sought to rescue childhood innocence from industrialization and has been shaping policy and practice ever since (Platt, 1969). As Hunt (1999) explains, these "moral regulation projects are an interesting and significant form of politics in which some people act to problematise the conduct, values, or culture of others and seek to impose regulations upon them" (p. 1). The historical and contemporary projects to protect children from the potential dangers of media reflect the Western cultural attachment to childhood innocence and the enduring belief that it is threatened by social change and popular culture (Garlen, 2019).

In the United States, one of the first waves of public concern over the media's influence on young people was a response to the penny press, which mass-produced inexpensive newspapers and sparked concern by sensationalizing crime and horror (Bogart, 1972, p. 493). However, it was the rise of the film industry in the early 20th century that gave way to the first organized public reform project. By the 1920s, debate about the movie "problem" began circulating in academic and popular discourse (Luke, 1990). Concerns included the potential effects of exposure to depictions of violence or interpersonal discord, the impact of movie viewing on school performance and attendance, eyestrain, and unsanitary cinema conditions (Luke, 1990). As Geiger (1923) asserted, these dangers constituted an "unparalleled assault" on society's most valuable assets, namely, "its innocency and its youth" (p. 79). For Johnson (1917), the responsibility for protecting children from these potential harms lay not with the film industry 
but with mothers, who were to organize "clean, wholesome, entertaining, and instructive" movie performances (p. 11).

These concerns led to the Payne Fund studies, the first comprehensive study of the effects of movies on the behaviour of children and adolescents. Initiated in 1929 and published in 1933, the research did not find a direct causal effect between movies and antisocial or criminal behaviour; rather, the influence of the media could only be understood in the context of individual experiences (Luke, 1990). Nevertheless, the study concluded that films contained "too much sex and crime and love" for children (Charters, 1933, p. 60). In spite of these tempered findings, the research was instrumental in the enforcement of the previously established Motion Picture Production Code, which outlined moral guidelines for the film industry and led to decades of censorship (Nichols, 2006). This code was replaced in 1968 by the Motion Picture Association's rating system designed to help parents decide what films were appropriate for their children.

By the 1950s, the increasing ubiquity of television was sparking similar panic about its potential effects on young viewers. As Bogart (1973) observed, "with the advent of television, the debate over the influence of the media was raised to a new plane of intensity" (p. 493). Concerns about television, not only as an instrument of entertainment but a commercial and political tool, raised questions about its possible effects. One survey conducted by the $\mathrm{Na}-$ tional Association of Educational Broadcasters reported that "crime and horror" accounted for 10\% of programming across four major U.S. cities (Murray, 1973, p. 472). Such concerns led to a 1954 congressional inquiry into juvenile delinquency, which concluded that crime and violence on television could be detrimental to young viewers and urged broadcasters to reduce violent content. However, subsequent surveys conducted by the same Senate committee in 1961 and 1964 found that such content had increased (Murray, 1973).

In response to these concerns, Congress commissioned the Surgeon General's Scientific Advisory Committee on Television and Social Behavior. The results, while acknowledging that television was only one of many factors that may contribute to violence in society and aggression in individuals, nonetheless raised concern about the prevalence of violent content in programming (United States, 1972). The Federal Communications Commission strongly urged limiting violent programming, but as television content was mostly protected under the First Amendment, networks were left to self-regulate. Meanwhile, television was growing increasingly ubiquitous; by the early 1970s, census figures estimated that $96 \%$ of the households in the United States contained at least one television set, while in families with young children, the television ownership rate approached 99\% (Murray, 1973).

However, it wasn't until 1996 that legislative action was taken in the United States to limit the negative influences of television on young viewers. To assist parents in supervising the television viewing habits of their children, Congress included a provision in the Telecommunications Act of 1996 that required a rating system for programming that included sexual, violent, or otherwise indecent content and mandated that all new television sets be equipped with a V-chip that would allow parents to screen out such programming (Emeritz et al., 2001). By this time, concern was also growing about the effects of advertising and Internet data collection on children. Policymakers and children's advocates began scrutinizing the data collection policies of Internet service providers (Turner, 2020). As a result, Congress passed the Children's Online Privacy Protection Act of 1998 (COPPA), which required websites or other online services directed to children under 13 to provide notice and obtain parental consent before collecting personal information.

In 2000, Harvard psychologist Susan Linn founded the Campaign for a Commercial-Free Childhood (CCFC), a nonprofit organization that sought to end marketing to children. Over two decades the organization has won a number of high-profile victories against toy and entertainment corporations that have resulted in changes to marketing practices. Most recently, CCFC lobbied for a federal investigation of YouTube that resulted in a 170-million dollar court settlement to limit data collection and advertising practices related to children's content (Singer \& Conger, 2019). This case reflects the shift in public concern over the potential effects of media as the media environments shifted from a network system of corporate controlled distribution into a decentralized networked system where users have more control over how content is created, shared, and consumed (Jenkins, 2006). In particular, YouTube, which boasts over 2 billion monthly users who watch more than 250 million hours of content per 
day in 100 different countries (Spangler, 2019), has drawn criticism for its practice of monetizing video content, which allows content creators to share in revenue from advertisements shown before, during, or alongside a video. In 2006, just a year after its launch, YouTube was acquired by Google, which implemented monetization as a strategy to transform the site into a revenue-generating platform (Gerhards, 2017). Monetization has been a lucrative strategy, considering that spending on digital advertising geared at children totalled 900 million U.S. dollars in 2018 (Guttmann, 2019; Markijke De Veirman et al., 2019).

YouTube's popularity with children has been a source of significant controversy, particularly due to the fact that updated COPPA regulations require users to be over the age of 13 since Google collects and markets user data (U. S. Federal Trade Commission, 2013). In response to the new legislation and concerns of advocacy groups, YouTube introduced the YouTube Kids app in 2015 as a space where children could safely browse content selected based on algorithms and human reviewers. The application comes with a number of parental controls that allow for parents to curate what content their children can and cannot see, set locks and time limits, and choose the age range that best suits the child. In spite of these measures, YouTube has continued to draw criticism. As Burroughs (2017) has pointed out, YouTube Kids creates an environment where "children are now directly advertised to, creating a political space of branding and lucrative children's marketing" (p. 2). Ultimately, YouTube Kids is intentionally engineered to influence infants' patterns of consumption.

Beyond such marketing practices, what sparked the most public outrage was the "startling videos" making their way past the app's child-friendly content filters, as first reported by The New York Times in 2017. In the article, Maheshwari (2017) described multiple examples of "videos with well-known characters in violent or lewd situations and other clips with disturbing imagery, sometimes set to nursery rhymes" (para. 7). For example, one of these disturbing videos showed puppy characters from a popular animated preschool television called PAW Patrol committing suicide, with one walking off a roof after being hypnotized by a demon-possessed doll from an adult horror movie (Maheshwari, 2017). Another example was a video in which a clay caricature of the comic superhero Spider-Man is shown urinating on the character Elsa from Disney's popular animated film Frozen. In response to this unsettling trend, James Bridle (2017) published a scorching post on Medium entitled "Something is Wrong on the Internet," in which he asserted that "someone or something or some combination of people and things is using YouTube to systematically frighten, traumatise, and abuse children" (para. 5). Bridle identified examples of the disturbing knockoffs of familiar cartoon characters and expressed concern about the weirdness of unboxing videos, such as the wildly popular Surprise Egg videos, previously described by another journalist as "incredibly seductive, in a very innocent-but-addictive way" (Amlen, 2014, para. 3). While unboxing videos lack the outright vulgarity of the strange parodies, they celebrate consumerism in a way that some adults find equally disturbing. According to Michael Rich, director and founder of the Center on Media and Child Health at the Boston Children's Hospital, unboxing videos teach children "to want things. It feeds into the 'give me' culture" (Lopez, 2019, para. 7).

Together, the rampant commercialization and predatory content creation has sparked concern among parents and advocates regarding children's use of and engagement with social media (Craig \& Cunningham, 2017). Specifically, Bridle (2017) claims that "very young children" are "being deliberately targeted with content which will traumatise and disturb them" (para. 56). While we do not necessarily share Bridle's (2018a) alarmist assertion that YouTube Kids is symptomatic of a "new Dark Age" that is making the world a more dangerous place for children and adults alike, we find salient his observation that, when it comes to the infrastructure of children's media experiences, "we're still struggling to find a way to even talk about it, to describe its mechanisms and its actions and its effects" (Bridle, 2017, para. 62). Toward that end, we wonder how we might initiate a broader, more balanced conversation about contemporary childhood in a time of constantly changing social media and technology trends. In what follows, we explore one entry point into such a discussion through our analysis of anonymous user responses to Bridle’s 2018 TED Talk.

\section{Unboxing the commentary}

The primary data for our analysis consisted of 21,113 user comments posted in response to James Bridle's (2018b) TED Talk “The Nightmare Videos of Children's YouTube-And What's Wrong with the Internet Today." We chose 
to analyze responses to this video in particular for a few reasons. First, viewer comments are disabled on the actual videos targeted toward children, so we required an alternative entry point into the discourse around children's YouTube. Second, Bridle's video was very popular, generating a large number of viewers, so this allowed for a diverse range of responses. The data included two sets of viewer comments: a smaller set (56) from the TED website and a larger set $(21,057)$ from YouTube.

The purpose of analyzing the video comments was to explore the discursive landscape surrounding children's use of YouTube by examining how viewers responded to Bridle's claims. We used thematic content analysis to "unbox" or dissect the discussion. Following Braun and Clarke (2006), we familiarized ourselves with the data through multiple views of the video and an initial review of comments. During this review many comments were excluded, including those not substantive enough to yield insights (short, off-topic, incoherent), not written in English, or containing profanity or discriminatory language. As most of the posted comments met these criteria, the exclusion process allowed us to narrow down the data to a significantly smaller set of 1,719 substantive and relevant comments on which we focused our analysis.

Next, initial codes were generated for this data set. Each comment was pasted into a spreadsheet and codes were recorded in the adjacent columns. Once codes were generated for all entries, we reviewed emergent themes. We calculated the distribution of themes across the entire dataset to identify dominant themes. The nondominant themes (those with a frequency of 64 or less) included denial, childhood agency and empowerment, child incompetence, and effects on early learning and mental health. The dominant themes (frequency of 228 or higher) are recorded in Table 1 below.

As the table shows, we identified two dominant overarching themes among the high-frequency subthemes: risk and responsibility. Under the theme of risk, alarm (expressions of concern over children's loss of innocence as a result of inappropriate content) was prevalent, appearing 502 times. The frequency of this subtheme was not surprising given the alarmist tone of Bridle's talk, in which he describes software that can "automatically generate kids' worst nightmares" and children "being traumatized, becoming afraid of the dark, becoming afraid of their favorite cartoon characters" as a result of exposure. A closely related but slightly less frequent subtheme was addiction and dependency, which we also found consistent with Bridle's assertions that unboxing videos are "like crack for little kids." Both themes speak to the viewers' deep concerns, and we take this as evidence that both Bridle's accusations against YouTube and reactions to them are consistent with the historical discourses of risk that have framed moral panics over children's media use.

Table 1. Dominant Themes from Thematic Analysis

\begin{tabular}{|l|l|l|}
\hline Dominant Themes & Subthemes & Frequency \\
\hline \multirow{3}{*}{ Risk } & Alarm & 502 \\
\cline { 2 - 3 } & Addiction and dependency & 228 \\
\hline \multirow{3}{*}{ Responsibility } & Parental responsibility & 951 \\
\cline { 2 - 3 } & Corporate responsibility & 791 \\
\cline { 2 - 3 } & Societal responsibility & 342 \\
\hline
\end{tabular}

Because the prevalence of risk-oriented discourses is well documented by historical trends, we focused our attention on the second and most prominent theme, responsibility. These comments were not unexpected given the question that Helen Walters, head of curation at TED, asks Bridle in the last minute of the video, which is, "Whose responsibility is education in this new world?" In other words, who is responsible for mitigating the risks that Bridle is alerting us to? Bridle's response is that it "is kind of up to all of us, that everything we do, everything we build, everything we make needs to be made in a consensual discussion with everyone who's avoiding it." Given Walters' 
direct question and his somewhat vague response, it is not surprising that many viewers chose to share their own answers. However, given the quantity of these responses, we saw an opportunity to explore how a fixation on blame is shaping contemporary public discourse related to children as digital media consumers. These comments could be categorized into three subthemes depending on who was identified as the responsible party: society (342), corporations (791), or parents (951). As we illustrate below, further analysis of these subthemes offers insight into how discourses of responsibility have limited, and continue to limit, the focus of public dialogue around children's media experiences.

\section{Societal responsibility}

The smallest subset of comments (342) reflected the belief that social institutions-such as schools and communities - should be responsible for equipping children with the skills and knowledge they need to navigate their digital worlds. Many commenters called for the need for more resources to teach parents, educators, and other adults how to use YouTube and other forms of media technology. As one commenter expressed, many adults lack these skills:

I think the biggest issue is the lack of "media competence." This is something every parent or teacher should teach. The problem here is: most of them do not even know how to utilize media properly, so how can they possibly teach this?

Most often, the problem was attributed to schools, which viewers felt should be better preparing students. As one commenter observed, "you're extremely lucky to be able to even learn how to type in school." As this commenter further asserted, schools are failing to teach the skills needed to provide appropriate media environments for children:

Most parents don't know how to work parental controls, and most parents don't know how to browse the internet properly and safely (most people still use horribly inefficient Google search terms that give them worse results because they don't understand how search engines work, for example), so they can't teach their children to do so.

The calls for a more media-literate society were also grounded in an understanding of technology as a ubiquitous part of children's lives, regardless of expert recommendations about when and how it should be used. For example, one commenter noted the contradictions between the advice given to parents and technology use in schools: "Children under the age of 7 should never touch an iPad' but yet they are used in kindergarten and by various developmental therapists." This attitude of acceptance was reflected in the moderate tone of many of the comments, many of which suggested that children could be taught how to integrate technology in beneficial ways. As one commenter stated, "It's how they are used and how they are integrated into life. The better strategy is to gradually teach kids how to use technology in a healthy way."

These comments primarily identified digital media literacy as a solution to the problems discussed by Bridle, with many viewers calling for more comprehensive education on technology, especially the structures and functions of YouTube and other social media corporations. Such demands for social institutions to take up the task of promoting digital media literacy are not new. Since the early 2000s, critical media literacy advocates like Kellner and Share (2007) have called for schools to foster students' abilities to be agents in navigating and producing media messages. They find it "highly irresponsible in the face of saturation by the internet and media culture to ignore these forms of socialization and education" (Kellner \& Share, 2007, p. 4).

The comments calling for digital media literacy mirror the public pleas that have arisen with each new visual media innovation since the birth of the film industry. In response to the Payne Fund studies, progressive educational reformers championed the adoption of film appreciation courses to teach critical viewing skills in the early $20^{\text {th }}$ century (Staiger, 2005). Decades later, the growth of television entertainment prompted similar campaigns. Even after numerous congressional hearings, a special report to the National Commission on the Causes and Prevention of Violence in 1969, and the large-scale study commissioned by the Surgeon General, Gerber et al. (1980) found it necessary to insist that teaching "creative resources and critical viewing skills" should "become the primary task of schooling" (p. 716). Yet, four decades later, Kellner and Share (2019) observed that, in spite of "criticisms of the 
distorted values, ideals, and representations of the world in popular culture, media education in $\mathrm{K}-12$ schooling has never been systematically established and developed in the United States" (p. 5). Thus, the viewers' comments reflect a history of calls for systematic media literacy, which remains "an unfulfilled challenge" (Kellner \& Share, 2019, p. 3).

\section{Corporate responsibility}

The next largest subset of comments (791) addressed YouTube's responsibility for regulating its content and marketing practices. Many of these commenters expressed concerns about how YouTube is not being held accountable for its content. For example, one viewer wrote:

YouTube just says "Sorry! We'll see to improve our algorithms." ... and then it's business as usual again. Why isn't a company that has zero costs for content, but keeps around $45 \%-55 \%$ of the advertising income made on the platform-and that's billions and billions and billions-why is this company not directly accountable?

Other commenters expressed the need for YouTube to implement strategies for more effectively screening and reviewing content, including the use of additional parental controls and more human monitoring. As one viewer wrote, "I agree completely with the use of humans to moderate videos on YouTube. YouTube have been very irresponsible in trying to leave that important and vital job to an algorithm." Another identified the problem as a lack of human ethics:

The issue I think is that machine learning systems don't have any ethics, so if they notice that a lot of people are flagging queer content as being inappropriate for minors, they assume it's inappropriate. but then the people making the weird creepy videos know what keywords to avoid getting around that.

As these examples illustrate, many commenters felt that relying on algorithms alone was not an effective way of evaluating content. As one commenter pointed out, YouTube has created algorithms it can't control, but the bad actors who are creating the inappropriate content are highly skilled at manipulating the same algorithms for their malicious purposes.

Other viewers focused on YouTube's responsibility toward users, criticizing the platform for prioritizing profit over providing appropriate content for child viewers. One commenter wrote, "YouTube has become just like any other power-hungry media platform, only caring about watch revenue. I doubt they'd care about the content being made as long as it's producing the big numbers." These commenters expressed a need for YouTube to apply additional resources toward identifying which users should be allowed to provide content for children and creating clearer and more stringent guidelines that would enable children to view content freely without the threat of encountering inappropriate content. As one commenter noted, YouTube's actions aren't consistent with its own policies: "youtube [sic]: clearly states when signing up for an account that the youtube platform is not intended for children under 13 also youtube: demonetizes and takes down entire channels for not being kid friendly enough." Among these comments was a general sense that "the system is messed up" and that the policies that YouTube does have in place are ineffective. One commenter complained that they "got a strike" for a video of two people arguing, and "yet, these fake-disney [ sic] horror videos" get a "green light from the system." Many commenters expressed that, as one viewer wrote, "You Tube isn't really trying." In particular, the policies that require creators to identify whether content is child friendly were identified as ineffective.

These questions and comments regarding YouTube's obligation to protect children through self-regulation reflect a contemporary interest in corporate social responsibility (CSR), the expectation that corporations should act deliberately to enhance society and be conscious of the economic, social, and environmental effects of their operations. As Frederick (2018) notes, the United States has had a long-standing interest in CSR because its adherence to a free-market ideology creates conditions that "generate an increased expectation of social awareness and social services to be forthcoming from private enterprise" (p. 5). With the rise of the Internet and the increasing ubiquity of digital media, CSR demands in the 21st century have centered largely on social media platforms. YouTube, in particular, has been the subject of a number of high-profile controversies around creator content such as videos 
containing anti-Semitic imagery and other forms of offensive or extremist content, especially when these videos have ads attached to them. Public outcry over such videos has resulted in advertisers pulling their ads from the site (Leskin, 2020). After Bridle's (2017) public condemnation of YouTube Kids, YouTube announced that it would no longer allow monetization of videos that "made inappropriate use of family friendly characters" and later implemented a policy for flagging age-restricted content and blocking it from YouTube Kids (Popper, 2017, p. 2). In 2019, YouTuber Matt Watson revealed how assumed pedophiles were using comments to share vulgar remarks on videos of young girls, leading to further advertising withdrawals and YouTube's disabling of comments on all videos featuring children (Leskin, 2020).

In April 2019, YouTube CEO Susan Wojcicki released a statement declaring that her "top priority" was "responsibility" (Wojcicki, 2019, para. 1). Wojcicki acknowledged that the new policy of disabling comments "impacted so many creators who we know are innocent" but "in the end, that was a trade-off we made because we feel protecting children on our platform should be the most important guiding principle" (para. 2). Yet, as Bergen and Shaw (2019) observe, it was a virtually impossible task to "nurture a growing community of demanding creators, while pledging to police troubling videos and protect millions of underage users who officially shouldn't even be watching" (para. 2). YouTube's efforts were met with anger by creators who stood to lose millions in ad revenue, as well as free speech advocates concerned about censorship (York, 2018). YouTube's attempts to be socially responsible for protecting children highlights the "existential quandary" of a corporation trying to protect children while maintaining the "neutrality that it needs to thrive" (Bergen and Shaw, 2019, para. 2). This dilemma reflects a central issue in the historical discourse around children's access to and exposure to media, which is the tension between protecting children and preserving freedom of expression.

\section{Parental responsibility}

The largest subset of comments placed the primary responsibility for protecting children online with parents. These comments were divided between those who believed greater parental supervision was required and those who felt that young children should not have access to YouTube at all. The latter group, while in the minority, expressed strong opinions regarding children's use of the social media platform. One commenter wrote, "You do know there is a reason for the age limitation on YouTube right? Another agreed, stating "YouTube isn't for kids." Another commenter scolded, "I cannot even remotely understand how someone could let toddlers use YouTube or the internet in the first place. What the heck is wrong with you guys?"

More commonly, commenters expressed concerns about parental presence and the level of supervision provided when children were using the site. A common complaint was that instead of monitoring their children, parents are using YouTube to keep children occupied when they are busy doing other things. As one commenter expressed, "I wouldn't say that you shouldn't let young children use YouTube at all. But don't let them alone with it. Use it as bonding and curate the videos. A tablet isn't a babysitter." Another viewer expressing a similar sentiment wrote, "I don't think there's anything wrong with letting them watch some YouTube, as long as it's in an appropriate quantity and of appropriate quality." One commenter asserted, "If you're going to let little kids watch YouTube obviously you need to watch it with them; you wouldn't leave them to play at the park by themselves, don't leave them alone on an unregulated public website."

All of these comments placed the responsibility for vetting content and monitoring children's usage with the parents. Further emphasizing this point, one parent explained how their interventions had led to their child's appropriate viewing habits: "I stopped letting him watch YouTube but I also closely monitored what videos he was watching. He didn't see anything bad because I hate autoplay. You can't expect YouTube to monitor kids that's a parents [sic] job." Similarly, another parent described their technology supervision practices, condemning parents who don't "take the time to preview, archive appropriate material in playlists, and ACTUALLY WATCH the videos with their children, instead of handing their children a mobile device and then doing their own thing on their own devices."

Among the comments expressing concern about parental supervision, many comments specifically critiqued con- 
temporary parenting practices. For example, one commenter shared their critical opinions on permissive parenting:

It's not ok to give the kid all that freedom. They need to learn to know their limits. If you give them anything they want just because they are happy, you'll spoil them. Discipline is a very important yet not popular value. People nowadays say limitations are bad and people should do whatever they want when in reality they need to learn to behave and respect.

Similarly, another commenter described how parental indulgence and inattention leads to excessive use of technology, even at the park, where they observed "a bunch of 6-12 year olds sitting on slides and swings, using iPhones and iPads, with some even having headphones/earbuds in and watching videos, with their parents not even paying attention. It's actually happening." Many commenters identified parental laziness as the problem: "Kids need to get entertained and some parents are too lazy to do it themselves so they let YouTube do it." Another commenter claimed, "Parents throw them on a tablet to make them be quiet and make them become addicted to it."

As these examples illustrate, a sense of righteous disapproval about the ineptitude of today's parents permeated this set of comments. This proclivity to name poor parenting as a threat to the well-being of children and society has been a common theme in long-standing debates over the regulation of media. For example, in summarizing the findings of the Payne Fund studies, W.W. Charters (1933) noted that one study on the social conduct and attitudes of movie fans found that "the influence of a motion picture is only one of several influences and the attitudes of children are a product of many influences" (p. 17). Among those many influences, Charters identified "native temperament, past experience, family ideals" and "community mores" as factors that could determine how social conduct is shaped by movies (p. 17). As he further asserted, "the home influence may be stronger than the movie in specific cases" (pp. 17-18). While the Payne Fund study's findings are decidedly ambiguous and do not directly implicate parents as being responsible for ensuring that movies don't "crash through and overpower the influence of the home, school, or the community," (p. 18), it can be inferred that combatting the potentially negative influences of movies and harnessing their positive effects largely depends on parents.

The early decades of television brought more explicit concerns regarding parental regulation. In her book The Plug-In Drug: Television, Children and the Family, anti-TV advocate Marie Winn (1977) expressed concerns about "the particular difficulty latter-day parents have in saying 'no' to their children" (p. 169). Winn asserted that "many of the difficulties parents face in controlling television are related to modern child-rearing trends and sociological tendencies-permissiveness, the diminishing authority of the family, the growth of the suburbs" (p. 172). Winn even went so far as to suggest that "had television existed a century ago, parents then, with their strong family structure and firm authoritarian ways, would have been able to keep it in hand" (p. 172). Like Charters' subtle reference to "family ideals," Winn's nostalgia for the authoritative rural family reflects a discourse of parental blame that privileges white, heteropatriarchal social structures and constructs poor and marginalized families as morally deficient.

The subsequent spread of digital media exaggerated the emerging tendency to blame parents for failing to provide their children with appropriate supervision and moral guidance. One notable example is child psychiatrist Robert Shaw's (2003) scathing indictment of contemporary parenting practices, The Epidemic: The Rot of American Culture, Absentee, and Permissive Parenting, and the Resultant Plague of Joyless, Selfish Children. Shaw asserts that modern parents fail to provide limits for their children or even allow them to experience frustration, at the expense of their moral development. To make matters worse, Shaw argues, "they abandon their children to the influence of the media-children waste so much time on so much mind-numbing electronic entertainment as television and video games that their literacy, social development, and creativity are all inhibited" (p. 4). A new edition of Shaw's book was published in 2013, which, like the largest set of comments made in response to Bridle's talk, illustrates that parental blame continues to be relevant in contemporary discourses of children placed "at risk" by media exposure. 


\section{Unboxing childhood: Risk, responsibility, and agency}

If we consider the data described here a microcosm of the larger discursive landscape surrounding contemporary childhood, then our unboxing of this commentary on YouTube reveals that the dialogue has remained largely the same throughout a century of moral panic over children's media exposure. As we unpacked the themes of responsibility that were contained within the sets of comments, what was most striking to us were the components that were missing. Across the large set of comments we analyzed, there was little discussion about children's response to the videos or debate about their processes or potential effects, either positive or negative. Instead, the conversation was framed by the question of who is to blame. Therefore, in conducting this study, we have come to understand that our findings speak less to the phenomenon of unboxing videos and YouTube Kids specifically and more to the need to "unbox" the discourse on childhood in the digital age. It is no wonder that, as Bridle asserts, "we're still struggling to find a way to even talk about it, to describe its mechanisms and its actions and its effects," because, as our analysis reveals, we've essentially been having the same conversation for the last one hundred years. Although public concerns and advocacy campaigns have sparked some policy and legal changes, the emphasis on risk and responsibility that has persisted for so many years has not brought us closer to understanding relationships between children and media or how our fears and responses to those relationships are shaped by social constructs of what childhood is and "should" be.

At the heart of these concerns about protecting children from the harmful effects of media is an enduring belief in innocence as the appropriate condition of childhood, a construct that has been continually rewritten through a persistent narrative that childhood itself is at risk (Garlen, 2019). Indeed, Bridle's claims against the Internet are not unlike Joseph Geiger's accusation a century before; that an "unparalleled assault" is being waged "on society's most valuable assets, namely, its innocence and its youth" (p. 79). Bridle's anxieties about digital media content, like the historical concerns about both film and television, centre on violence. Beyond the "violence being done to children" by the rogue content creators, Bridle (2017) expresses concern that "this is just one aspect of a kind of infrastructural violence being done to all of us, all of the time" (para. 62). This recurring theme of violence, from sex and crime and love on films and television shows to disturbing animations and predatory advertisements on tablet screens, reflects a protective impulse and an ongoing fear of exposure, which threatens childhood innocence understood as a state of "not-knowing" (Garlen et al., 2020). As historical debates illustrate, what is typically feared is exposure to "adult" social realities, particularly relating to sex. The need to protect children from the potential harms of such "adult" knowledge has been the driving force behind debates about how children's media use should be regulated. As illustrated by this study, the question of who is responsible for mitigating the perceived risks that media poses for children has profoundly shaped and more importantly, limited, public discourse on the relationship between childhood and media, which continues to be premised on protection. Although questions about the ethical obligation of families, corporations, and societies to children are certainly valid and worthy of debate, this protective approach "over-simplifies the complexity of our relationship with media and takes away the potential for empowerment that critical pedagogy and alternative media production offer" (Kellner and Share, 2007, p. 60).

As our inquiry suggests, the protective imperative that has driven panic over children's media use for nearly a century is still pervasive in contemporary discourse. Where young children in particular are concerned, digital technology has been accused of making childhood "toxic" (Palmer, 2015) and "hijacking" brain development (Kardaras, 2016). And yet, particularly with the dawn of a global pandemic that has increased demand for online entertainment and information, YouTube's reach among children continues to grow, especially among children under the age of 11 (Auxier et al., 2020). As one of the most significant sites of learning and socialization for children today, YouTube should be taken seriously as a product of "social production and struggle" (Kellner, 1998, p. 113), a medium that is both shaping and shaped by contemporary childhood. Maintaining an emphasis on risk is not likely to lead to a better understanding of children's media experiences or the role that digital media plays in their lives, including their potential effects. Therefore, we suggest that the discourse of protection, including the enduring figure of the unknowing innocent child, requires rethinking in order to begin a broader conversation about children's agency in social media platforms and society at large. If we seek to improve the digital lives of children, we must, as Egan and Hawkes (2009) argue, "take them seriously as 'knowers' in the world," and acknowledge 
that they are not simply ignorant objects in need of protection, but "reflexive and thoughtful social actors capable of taking part in a dynamic and dialogical exchange" (Egan and Hawkes, 2009, p. 395).

What would it mean to unpack and critically examine these constructs in order to facilitate a different kind of conversation about children and social media and work toward realizing the "unfulfilled challenge" of critical (digital) media literacy? Opening up the dialogue to new possibilities requires opening up the binary risk/benefit "box" to a more complex perspective that recognizes both the destructive potential and transformative possibilities of digital content creation and consumption. Toward that end, Craft (2012) proposes a view of children as agentic and "skilful collaborators, capable of knowledge-making as well as information-seeking” (p. 174). As Craft suggests, even in "a digital, marketized age, children and young people can be understood and recognised as creative and potent" (p. 189). However, a focus on understanding how children engage with social media, navigate sources of information and entertainment, and produce their own digital content requires that the discussion around children's media use move beyond blame. Focusing on who is to blame for children's media "exposure" is a defensive stance that detracts from what actions can and should be taken. A more generative starting point might be the very question that guided this study: what can be learned? More specifically, we might ask what can be learned about how children are experiencing and transforming their digital worlds? Such a question could move the dialogue away from judgment and toward curiosity about how children are using and making meaning of new media.

Shifting the debate about contemporary childhood away from risk and responsibility and toward agency does not mean that media conglomerates should be given unconditional authority when it comes to regulating content for children, or that government intervention is never justified. Rather it means reframing the debate about what can and should be changed around an "unboxed" construct of childhood-one that seeks to understand and empower rather than to limit and confine. As Egan and Hawkes (2009) assert, such a paradigm shift would "require that we stop using the protection of children to legitimate surveillance and social control more broadly" (p. 397). Emancipating childhood from such constraints is no easy task, considering the Western cultural investment in the discourses of child protection and innocence (Garlen, 2019, Duschinsky, 2013). Yet, without an acknowledgment of children's capacity to act independently and make their own choices, a truly critical media literacy cannot be advanced.

\section{Note}

This work was supported by internally restricted research funds provided by Carleton University. 


\section{References}

Amlen, D. (2014). Why unboxing videos are so satisfying. Yahoo Finance. https://finance.yahoo.com/news/why-unboxing-videos-are-so-satisfying-99561095209.html

Auxier, B., Anderson, M., Perrin, A., \& Turner, E. (2020). Parental views about YouTube. Pew Research Center. https://www.pewresearch. org/internet/2020/07/28/parental-views-about-youtube/

Bergen, M., \& Shaw, L. (2019). YouTube CEO Susan Wojcicki responsibility push angers PewDiePie. Bloomberg, December 24. https:// www.bloomberg.com/news/articles/2019-12-24/youtube-ceo-susan-wojcicki-responsibility-push-angers-pewdiepie

Bogart, L. (1972). Warning: The Surgeon General has determined that TV violence is moderately dangerous to your child's mental health. The Public Opinion Quarterly, 36(4), 491-521. https://doi.org/10.1086/268035

Braun, V., \& Clarke, V. (2006). Using thematic analysis in psychology. Qualitative Research in Psychology, 3, 77-101. https://doi. org/10.1191/1478088706qp063oa

Bridle, J. (2017). Something is wrong on the Internet. Medium. https://medium.com/@jamesbridle/something-is-wrong-on-the-internetc39c471271d2

Bridle, J. (2018a). A new dark age: Technology and the end of the future. Verso.

Bridle, J. (2018b). The nightmare videos of children's YouTube-and what's wrong with the internet today [TED Talk]. https://www.ted.com/ talks/james bridle the nightmare videos of children $s$ youtube and what $s$ wrong with the internet today

Burroughs, B. (2017). YouTube Kids: The app economy and mobile parenting. Social Media + Society. https://doi. org/10.1177/2056305117707189

Charters, W. (1933). Motion pictures and youth: A summary. Macmillan.

Clark, J. (2019). Physical activity and screen time among Canadian children and youth, 2016 and 2017. https://www150.statcan.gc.ca/n1/ pub/82-625-x/2019001/article/00003-eng.pdf

Cohen, S. (1972). Folk devils and moral panics: The creation of the mods and rockers. Oxford.

Common Sense Media. (2017). The Common Sense census: Media use by kids zero to eight. https://www.commonsensemedia.org/sites/ default/files/uploads/research/csm zerotoeight fullreport release 2.pdf

Craft, Anna (2012). Childhood in a digital age: creative challenges for educational futures. London Review of Education, 10(2), 173-190.

Craig, D., \& Cunningham, S. (2017). Toy unboxing: Living in a(n unregulated) material world. Media International Australia, 163(1), 77-86. https://doi.org/10.1177/1329878x17693700

Duschinsky, R. (2013). Childhood innocence: Essence, education, and performativity. Textual Practice, 27(5), 763-781. https://doi.org/1 $\underline{0.1080 / 0950236 X .2012 .751441}$

Emeritz, R., Tobias, J., Berthot, K., Dolan, K., \& Eisenstadt, M. (Eds.). (2001). The Telecommunications Act of 1996: Law and legislative history. Pike \& Fisher.

Frederick, W. C. (2018). Corporate social responsibility: From founders to millennials. In Corporate social responsibility (Vol. 2; pp. 3-38). Emerald. https://doi.org/10.1108/S2514-175920180000002001

Garlen, J. C. (2019). Interrogating innocence: "Childhood" as exclusionary social practice. Childhood, 26(1), 54-67. https://doi. org/10.1177/0907568218811484

Garlen, J. C., Chang-Kredl, S., Farley, L., \& Sonu, D. (2020). Childhood innocence and experience: Memory, discourse and practice. Children and Society. https://doi.org/10.1111/chso.12428

Geiger, J. (1923). The effects of the motion picture on the mind and morals of the young. International Journal of Ethics, 34(1), 69-83. https://doi.org/10.1086/intejethi.34.1.2377236

Gerbner, G., Gross, L., Signorielli, N., \& Morgan, M. (1980). Television violence, victimization, and power. American Behavioral Scientist, 23(5), 705-716. https://doi.org/10.1177/000276428002300506

Hall, S. (1978). Policing the crisis: Mugging, the state, and law and order. Macmillan.

Hunt, A. (1999). Governing morals: A social history of moral regulation. Cambridge University Press.

Jaakkola, M. (2020). From vernacularized commercialism to kidbait: Toy review videos on YouTube and the problematics of the mash-up genre. Journal of Children and Media, 14(2), 237-254. https://doi.org/10.1080/17482798.2019.1693409

Jenks, C. (1996). Childhood. Routledge.

Jenkins, H. (2006). Convergence culture: Where old and new media collide. NYU Press.

Johnson, J. S. (1917). Children and their movies. Social Science Review, September, 11-12.

Kardaras, N. (2016). Glow kids: How screen addiction is hijacking our kids-and how to break the trance. St. Martin's Press.

Kellner, D. (1998). Multiple literacies and critical pedagogy in a multicultural society. Educational Theory, 48(1), 103-123.

Kellner, D., \& Share, J. (2007). Critical media literacy, democracy, and the reconstruction of education. In D. Macedo \& S. R. Steinberg (Eds.), Media literacy: A reader (pp. 3-23). Peter Lang.

Kellner, D., \& Share, J. (2019). The critical media literacy guide. Brill | Sense. https://doi.org/10.1163/9789004404533 
Kelly, H. (2014). The bizarre, lucrative world of "unboxing" videos. CNN, February 13. https://www.cnn.com/2014/02/13/tech/web/youtube-unboxing-videos/index.html

Kollmeyer, B. (2015, April 7). Ready to be hypnotized by "toddler crack"? MarketWatch. https://www.marketwatch.com/story/ready-toget-hypnotized-by-toddler-crack-2015-04-07

Krinsky, C. (2008). Introduction. In C. Krinsky (Ed.), Moral panics over contemporary children and youth (pp. 1-8). Ashgate.

LaFrance, A. (2017). The algorithm that makes preschoolers obsessed with YouTube Kids. The Atlantic, July 25. https://www.theatlantic. com/technology/archive/2017/07/what-youtube-reveals-about-the-toddler-mind/534765/

Leskin, P. (2020). YouTube is 15 years old. Here's a timeline of how YouTube was founded, its rise to video behemoth, and its biggest controversies along way. Business Insider, May 30. https://www.businessinsider.com/history-of-youtube-in-photos-2015-10

Lopez, C. (2019). What those hugely popular unboxing videos could be teaching kids. WBUR, February 25. https://www.wbur.org/artery/2019/02/25/unboxing-videos-teach-kids-youtube

Luke, C. (1990). Constructing the child viewer: A history of the American discourse on television and children, 1950-1980. Praeger.

Maheshwari, S. (2017). On YouTube Kids, startling videos slip past filters. The New York Times, November 4. https://www.nytimes. com/2017/11/04/business/media/youtube-kids-paw-patrol.html

Marsh, J. (2015). "Unboxing" videos: Co-construction of the child as cyberflâneur. Discourse: Studies in the Cultural Politics of Education, 37(3), 369-380. https://doi.org/10.1080/01596306.2015.1041457

Murray, J. (1973). Television and violence: Implications of the Surgeon General's research program. The American Psychologist, 28(6), 472-478. https://doi.org/10.1037/h0035086

Nichols, J. (2006). Countering censorship: Edgar Dale and the film appreciation movement. Cinema Journal, 46(1), 3-22. https://doi. org/10.1353/cj.2007.0003

Nicoll, B., \& Nansen, B. (2018). Mimetic production in YouTube toy unboxing videos. Social Media + Society. https://doi. org/10.1177/2056305118790761

Palmer, S. (2015). Toxic childhood: How the modern world is damaging our children and what we can do about it. Orion.

Platt, A. (1969). The rise of the child-saving movement: A study in social policy and correctional reform. The Annals of the American Academy of Political and Social Science, 381(1), 21-38. https://doi.org/10.1177/000271626938100105

Popper, B. (2017). YouTube says it will crack down on bizarre videos targeting children. The Verge, November 9. https://www.theverge. com/2017/11/9/16629788/youtube-kids-distrubing-inappropriate-flag-age-restrict

Postman, N. (1982). The disappearance of childhood. Delacorte Press.

Ramos-Serrano, M., \& Herrero-Diz, P. (2016). Unboxing and brands: YouTubers phenomenon through the case study of EvanTubeHD. Prisma Social, 1, 90-120. https://revistaprismasocial.es/article/view/1315

Rose, N. S. (1990). Governing the soul: The shaping of the private self. Routledge.

Shaw, R. (2003). The epidemic: The rot of American culture, absentee, and permissive parenting, and the resultant plague of joyless, selfish children. Harper Perennial.

Singer, N., \& Conger, K. (2019). Google is Fined $\$ 170$ million for violating children's privacy on YouTube. The New York Times, September 4. https://www.nytimes.com/2019/09/04/technology/google-youtube-fine-ftc.html

Sloane, G. (2015). "Unboxing” YouTube marketers are accused of tricking kids. Adweek, May 22. https://www.adweek.com/digital/unboxing-youtube-marketers-are-accused-tricking-kids-164967/

Spangler, T. (2019). YouTube now has 2 billion monthly users, who watch 250 million hours on TV screens daily. Variety, May 3. https:// variety.com/2019/digital/news/youtube-2-billion-users-tv-screen-watch-time-hours-1203204267/

Staiger, J. (2005). Media reception studies. NYU Press.

Timsit, A. (2018). The addictive world of toy unboxing videos gives kids the wrong idea about how to have fun. Quartzy, September 3. https://qz.com/quartzy/1374703/unboxing-videos-will-take-over-the-world/

United States. (1972). Television and growing up: The impact of televised violence. Surgeon General's Scientific Advisory Committee on Television and Social Behaviour, Vol. 3. DHEW Publication No. HSM 72-9090.

U. S. Federal Trade Commission. (2019). Revised children's online privacy protection rule goes into effect today. https://www.ftc.gov/ news-events/press-releases/2013/07/revised-childrens-online-privacy-protection-rule-goes-effect

Winn, M. (1977). The plug-in drug. Viking Press.

Wojcicki, S. (2019, April 30). Addressing creator feedback and an update on my 2019 priorities [Blog post]. YouTube. https://blog.youtube/inside-youtube/addressing-creator-feedback-and-update

York, M. (2018). Free speech on YouTube. Videomaker, 32(8), 2.

Zelizer, V. (1985). Pricing the priceless child: The changing social value of children. Basic Books. 